\title{
Congenital tracheal stenosis \& associated cardiac anomalies: operative management \& techniques
}

\author{
Aditya Sengupta, Raghav A. Murthy \\ Department of Cardiovascular Surgery, Icahn School of Medicine at Mount Sinai, New York, NY, USA \\ Contributions: (I) Conception and design: All authors; (II) Administrative support: A Sengupta; (III) Provision of study materials or patients: All \\ authors; (IV) Collection and assembly of data: All authors; (V) Data analysis and interpretation: All authors; (VI) Manuscript writing: All authors; (VII) \\ Final approval of manuscript: All authors. \\ Correspondence to: Raghav A. Murthy, MD, DABS, FACS. Assistant Professor, Director of Pediatric Cardiac Transplantation/Division of Pediatric \\ Cardiac Surgery/Department of Cardiovascular Surgery, Icahn School of Medicine at Mount Sinai, 1184 Fifth Avenue, Box 1028, New York, NY \\ 10029, USA. Email: raghavamurthy@gmail.com.
}

\begin{abstract}
Congenital tracheal stenosis can lead to symptomatic airway obstruction in children and often mandates surgical correction. Over the past half-century, numerous tracheal reconstruction techniques have been developed, including tracheal resection with end-to-end anastomosis (for short-segment complete tracheal stenosis), patch tracheoplasty, slide tracheoplasty, and homograft and autograft augmentation repairs. However, operative management of congenital tracheal stenosis is often complicated by the presence of congenital heart disease, the most common of which is pulmonary artery sling. When present concomitantly, combined repair of both defects is feasible and is currently the preferred approach. Questions have been raised about the optimal timing and sequence of surgery, and some have advocated staged repair for patients with complex associated cardiac lesions. However, evidence from the past two decades suggests that concomitant repair can be performed with excellent results. The current standard of care involves the use of cardiopulmonary bypass to simultaneously repair the tracheal defect using slide tracheoplasty and all associated cardiac anomalies. Advances in operative techniques and extracorporeal circulation, progressive understanding of the pathological basis of combined congenital tracheal and cardiac disease, and a multidisciplinary approach to patient care have all contributed to the successful outcomes seen in the modern era. This article describes the combined surgical correction of tracheal stenosis and double-outlet right ventricle-tetralogy of Fallot type in an infant, provides a detailed step-by-step description for performing a slide tracheoplasty along with various other less favored tracheoplasty techniques, and reviews the current literature discussing such combined repairs.
\end{abstract}

Keywords: Congenital tracheal stenosis (CTS); pulmonary artery sling (PAS); double-outlet right ventricle (DORV); slide tracheoplasty; tracheal autograft; patch tracheoplasty

Submitted Sep 03, 2019. Accepted for publication Oct 12, 2019.

doi: $10.21037 /$ jtd.2019.10.42

View this article at: http://dx.doi.org/10.21037/jtd.2019.10.42

\section{Introduction}

Congenital tracheal stenosis (CTS) can manifest in the neonatal period or infancy with symptoms of stridor or respiratory insufficiency, and occurs in approximately 1 in 64,500 cases (1). The severity of the stenosis and associated diagnoses dictate the prognosis and course of this lesion set. Some children require intubation and mechanical ventilation, and extracorporeal support is rarely required for rescue. CTS is often secondary to complete tracheal rings, where the posterior membranous trachea is absent and instead replaced by complete circular cartilaginous rings. Tracheal involvement with such rings can be either short- $(<30 \%$ of the total tracheal length) or long-segment. 


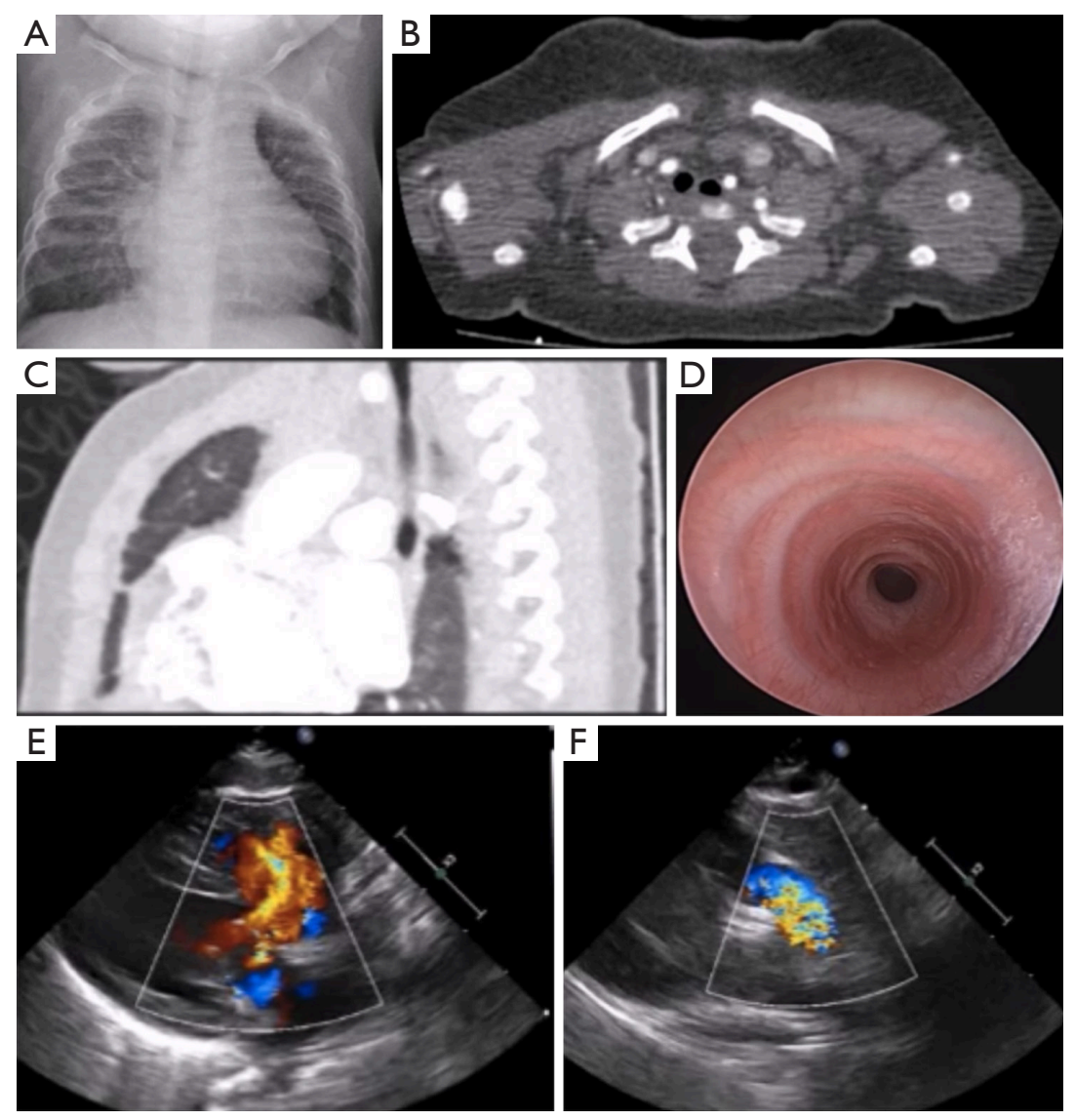

Figure 1 Pre-operative imaging studies. (A) Chest radiography showed an area of stenosis in the mid-trachea; (B,C) CT revealed a normalappearing trachea just above the thoracic inlet with mid-segment narrowing and reconstitution distally at the level of the carina; (D) bronchoscopy showed tracheal stenosis with eight complete tracheal rings; (E,F) echocardiography revealed a large VSD with an overriding aorta and severe PS, consistent with DORV-TOF. CT, computed tomography; VSD, ventricular septal defect; PS, pulmonary stenosis; DORV-TOF, double-outlet right ventricle-tetralogy of Fallot.

As this lesion is mechanical in nature, medical management is often futile ( $40 \%$ survival rate) and associated with a poor long-term prognosis (1). Surgical correction remains the mainstay of management. The timing of such surgery depends on various factors such as the severity of symptoms, age and weight of the child, extent of the stenosis, and associated major organ involvement and diseases. Significant cardiac anomalies are often simultaneously present and play an important role in determining the timing and outcomes of tracheal reconstructive surgery. The past half-century has witnessed the advent and evolution of numerous repair strategies for patients with combined disease. In this review, we start with a case of double-outlet right ventricletetralogy of Fallot type (DORV-TOF) and concomitant CTS, and highlight our techniques of combined, one-stage surgical repair. We then discuss the literature pertaining to combined tracheal and congenital cardiac surgery, and end with a brief overview of tracheal reconstruction techniques and specific considerations for patients with CTS and pulmonary artery sling (PAS).

\section{Case}

A 6-month-old infant with trisomy 21, DORV-TOF, and CTS secondary to complete tracheal rings presented with tachypnea, stridor, failure-to-thrive, and heart failure. Pre-operative evaluation by bronchoscopy and computed tomography (CT) showed mid-tracheal stenosis for eight complete tracheal rings, and echocardiography showed a large ventricular septal defect (VSD) with an overriding aorta and severe pulmonary stenosis (PS) (Figure 1). The patient underwent a slide tracheoplasty under 


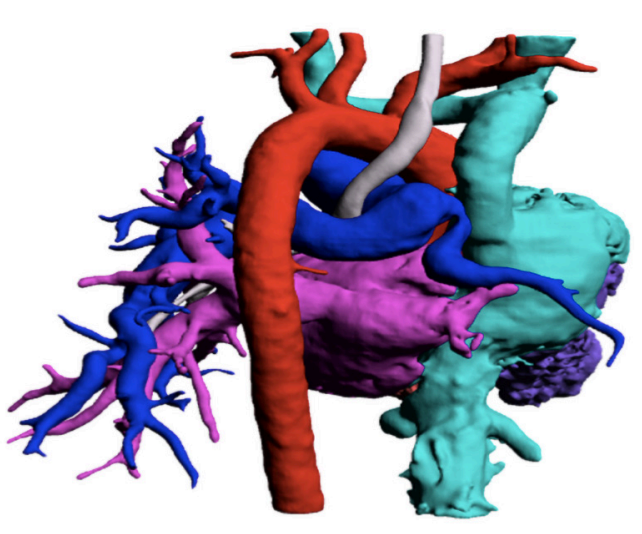

Figure 2 Shown here is a 3-dimensional CTA reconstruction of a ring-sling complex in an infant. Note the narrowed trachea (white), LPA sling, and RPA stenosis (blue). Also seen are the aorta (red), left atrium and pulmonary veins (pink), and both vena cava and right atrium (green). CTA, computed tomography angiography; LPA, left pulmonary artery; RPA, right pulmonary artery.

cardiopulmonary bypass (CPB) along with repair of all intra-cardiac defects as a single combined operation.

A standard median sternotomy was performed. A midline dissection was carried out, aided by the presence of bilateral superior vena cava (SVC) with no bridging veins. A generous piece of pericardium was harvested. The trachea was then dissected superiorly and inferiorly on its anterior surface with care taken not to extend the dissection laterally. The tracheal stenosis was identified, followed by sub-carinal dissection. A Montgomery suprahyoid release was performed. The midpoint of the tracheal stenosis was identified using bronchoscopy and marked. Following institution of $\mathrm{CPB}$, the trachea was divided at the midpoint. Further dissection was carried out, superiorly and inferiorly, until the normal membranous part of the trachea was seen. The posterior trachea was then divided in the midline distally, and a counter incision was made proximally on the anterior surface. 5-0 Vicryl sutures were then used to perform a slide tracheoplasty. The left SVC (LSVC) and inferior vena cava (IVC) were cannulated; the right SVC (RSVC) and aorta were clamped, and an oblique right atriotomy was performed. A bicuspid, dysplastic pulmonary valve was found following pulmonary arteriotomy; this was then extended to a transannular infundibulotomy. Right ventricular outflow tract (RVOT) muscle was resected, and a GoreTex patch was used for VSD closure. The previously harvested pericardial patch was then used as a transannular patch. The patient was subsequently weaned from $\mathrm{CPB}$ uneventfully.

Post-repair bronchoscopy revealed a wide-open airway with appropriate healing and minimal granulation tissue. The patient is currently 3 years post-repair and doing well. This case validates the feasibility of combined tracheal and congenital cardiac surgery with applications to a variety of lesions including PAS and DORV.

\section{Anatomy}

CTS occurs most often secondary to complete tracheal rings, which result from a defect in embryogenesis after the $8^{\text {th }}$ week of gestation (2). Here, the posteriorly-placed membranous trachea is absent and the cartilaginous trachea is circumferential (3). At these sites, the tracheal lumen can be reduced severely to diameters as small as 2 to $3 \mathrm{~mm}$ (4). Cantrell and Guild have categorized CTS into three types: generalized, funnel-like, and segmental stenosis (5). This lesion often presents with an associated cardiac anomaly, the most common of which is PAS (Figure 2). PAS is present in approximately a third of tracheal stenosis patients; conversely about $50 \%$ of patients with PAS have complete tracheal rings (6). The left pulmonary artery (LPA) originates anomalously from the right pulmonary artery (RPA) and courses posterior to the trachea as it heads towards the left lung, thus acting as a "sling" that pulls on and compresses the distal trachea and right main bronchus (7). However, as demonstrated by our case, a variety of other congenital cardiac anomalies may also be concomitantly present with tracheal stenosis, including TOF, VSD, complete atrioventricular canal, pulmonary atresia with VSD, DORV, and atrial septal defect (ASD) $(8,9)$.

\section{Operative management}

Medical management is futile in the treatment of symptomatic CTS leading to airway obstruction given the mechanical nature of the lesion, and is associated with at least $40 \%$ mortality (1). Surgical reconstruction is thus the mainstay of treatment. When associated with congenital cardiac defects, the optimal timing of surgical correction must be ascertained $(10,11)$. In the past, the risks and benefits of staged correction were argued against those of simultaneous repair. Proponents of the latter purported that prioritizing the cardiac anomaly usually leads to severe respiratory compromise post-operatively due to obstructive tracheal disease. Furthermore, tracheal surgery in a reoperative field is complicated by the presence of adhesions 
and a more challenging dissection. Similarly, prioritizing the tracheal lesion first increases the risk of wound dehiscence and infection secondary to an impaired microcirculation and hypoxia from the persistent cardiac anomaly $(12,13)$.

In the modern era, a single-stage combined repair can be successfully performed in all simple and the majority of complex heart defects. Challenges arise when such surgery has to be performed in neonates and infants with complex single ventricle anatomy. The contemporary tracheal operation of choice is the slide tracheoplasty. Our technique of performing this operation will be described in detail, and can be modified to accommodate associated tracheobronchial anomalies and stenoses. The other techniques for tracheal reconstruction will only be briefly discussed.

\section{Techniques of tracheal reconstruction}

Over the past 60 years, significant advances in pediatric tracheal surgery, coupled with the evolution of $\mathrm{CPB}$, have dramatically improved the prognosis of patients with CTS and associated cardiac anomalies. When the diseased trachea is less than $30 \%$ of the total tracheal length or involves fewer than 6-8 rings (short-segment tracheal stenosis), tracheal resection with primary anastomosis is the preferred method of tracheal reconstruction with $1-8 \%$ mortality (14). This has been demonstrated by the seminal works of Grillo and colleagues from the late 1960s to the current era, as well as by numerous other groups $(8,15-19)$. However, with long-segment tracheal stenosis, such an operation has dismal outcomes due to the excess tension placed on suture lines, resulting in increased complication and failure rates. Techniques to circumvent this problem have evolved over the years, and include pericardial patch tracheoplasty, autograft and homograft tracheoplasty, and slide tracheoplasty.

\section{Slide tracheoplasty}

Slide tracheoplasty was introduced in 1989 by Victor Tsang and Peter Goldstraw for the surgical management of complete tracheal rings (20). Over the past three decades, this technique has been refined, and is now the procedure of choice for CTS. We prefer to complete the tracheal surgery prior to repairing the cardiac defects during the same operation. This ensures a more secure airway with a larger endotracheal tube (ETT) and allows for easier coordination with other services, including Pulmonology and Otolaryngology. Furthermore, the heart is spared retraction after repair of any cardiac defects in order to expose the trachea. Disadvantages of such an approach include accumulation of bloody secretions in the airway during cardiac repair and concretion of these secretions following protamine administration. These issues can be easily tackled by a good post-operative bronchoscopic examination and aspiration of secretions. A detailed description of the technique adopted by the authors follows.

(I) Endotracheal intubation is performed by the anesthesia team with the "difficult airway" cart available. Prior to securing the tube, flexible bronchoscopy is performed. The ETT is placed just above the area of stenosis with care taken to avoid mucosal trauma from a deeply placed tube. The extent of the tracheal stenosis is then determined by performing a detailed and complete bronchoscopic evaluation. Neck lines are avoided as these are usually in the operative field. A shoulder roll is placed to allow gentle neck extension. Constant and open communication with the anesthesia team is crucial as the ETT will need to be moved during the procedure. Steroids are avoided during and after tracheal reconstruction;

(II) A median sternotomy is performed. The sternal retractor is placed with the bar facing inferiorly to allow for extension of the incision into the neck. A subtotal thymectomy is performed. A retraction stich is used superiorly to allow for better exposure;

(III) Pericardium is harvested, if required, for cardiac repair, and pericardial stay sutures are placed;

(IV) The innominate vein is dissected and encircled with umbilical tape to allow for retraction. The innominate artery, RPA, and aorta are similarly dissected and encircled with umbilical tape;

(V) The posterior pericardium is incised and the level 4 lymph nodes are excised. The trachea comes into view at this time. Care is taken to limit dissection only to the anterior tracheal surface. The lateral pedicles are left untouched as this contains the precarious blood supply as well as the recurrent laryngeal nerves;

(VI) The isthmus of the thyroid gland is dissected and divided. This maneuver provides an additional 0.5 to $1 \mathrm{~cm}$ of tracheal mobility;

(VII) A Montgomery-type supra-hyoid release is 
A

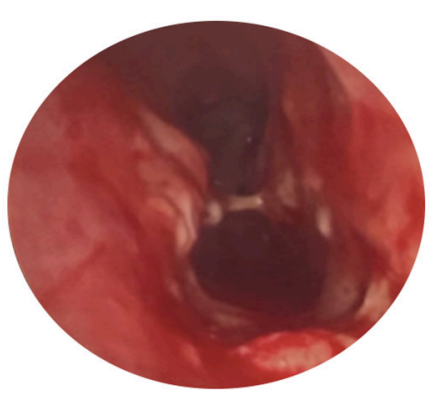

B

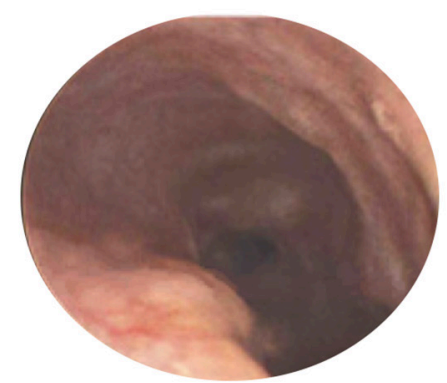

Figure 3 Post-operative bronchoscopy. (A) A figure-of-eight deformity seen on bronchoscopy performed immediately after slide tracheoplasty; (B) at 30 days, repeat bronchoscopy showed resolution of the previously seen deformity, along with a well-healed airway with minimal granulation tissue.

performed, as required, to provide additional tracheal mobility;

(VIII) The midpoint of the tracheal stenosis is now identified and marked with the help of bronchoscopy;

(IX) CPB is commenced and the patient is cooled to mild hypothermia;

(X) The mid-portion of the tracheal stenosis is then dissected circumferentially, taking care not to injure the esophagus posteriorly. The sub-carinal region and both bronchi are now dissected, thus allowing for good tracheal mobility and a tension-free anastomosis;

(XI) Tracheal transection is performed in the midportion of the stenosis. The posterior trachea is then dissected both superiorly and inferiorly. The inferior portion of the trachea is incised posteriorly while the superior portion is incised anteriorly (as described originally by Goldstraw). The tracheal segments may also be incised in the opposite manner to that described above (Grillo modification). However, we have found it easier to anastomose the segments by the former method. Care is taken to make sure that the incision is carried all the way to "normal" sized trachea to avoid leaving behind residual stenosis. The sharp corners of the trachea are rounded off. A trial of tracheal approximation is performed to determine the amount of tension placed on the suture line;

(XII) We prefer to perform the anastomosis with interrupted sutures. This allows for easier alignment of the trachea. Furthermore, a tear of a single suture site does not compromise the integrity of the repair. This technique requires additional time and is meticulous. The suture of choice is Vicryl or polydioxanone suture (PDS). The size of the suture depends on the size of the trachea; 5-0 is often used. Alternatively, a running suture can be performed. Prior to completing the anastomosis, the airway is aspirated proximally and distally. An appropriately sized ETT is then positioned in the midpoint of the reconstruction and secured in place. The superior and inferior extent of the repair are marked with Hemoclips to allow easy identification on radiography. The concluded anastomosis results in a trachea that is one-half the length and four times the area of the previous trachea. Bronchoscopy is then performed to clear secretions and blood, and identify residual stenoses or figure-of-eight deformities (Figure 3);

(XIII) The mediastinum is filled with saline and a leak test is performed with a Valsalva maneuver that raises the airway pressure to $35-40 \mathrm{cmH}_{2} \mathrm{O}$. Fibrin sealant is sprayed over the anastomotic line;

(XIV) The cardiac repair is now completed;

(XV) After chest closure, a "Grillo" guardian stitch is placed between the chin and the chest wall to maintain a neutral neck position;

(XVI) Post-operative considerations include avoiding steroids, maintaining lower peak pressures on the ventilator, and bronchoscopic evaluation prior to early extubation;

(XVII) The slide tracheoplasty is a versatile technique 
for repairing CTS. It can be modified to accommodate repair of bronchial stenoses and various other associated tracheobronchial malformations. Granuloma formation is sometimes seen post-repair, and some groups advocate the post-operative use of inhaled Ciprodex to minimize this complication (21). Mortality has been reported to be $\sim 1-9 \%$ by published series (6,22-27). Tracheal growth after this operation remains the same as normal tracheas, or about $0.42 \mathrm{~mm}$ per year (2).

\section{Tracheal homograft \& autograft techniques}

Tracheal homograft reconstruction was first performed by Klaus Herberhold in 1981. In the 1990s, this technique was popularized by a number of groups, including teams led by Martin Elliott and Jeffrey Jacobs (14). Here, the anterior part of the stenotic trachea is first excised. A tracheal homograft is then cut to size and sutured into place with interrupted horizontal absorbable monofilament sutures. Silastic stents are implanted simultaneously to provide internal support to the homograft until epithelialization is complete. These are usually removed $2-3$ months postoperatively. Mortality in the seminal series by Jacobs et al. of 24 children who underwent homograft reconstruction was $17 \%(28)$.

In contrast, the autograft technique, introduced by Backer and Mavroudis in 1998, uses tissue from the patient's distal trachea for reconstruction (29). Using a midline sternotomy along with a transverse collar incision, the trachea is exposed and CPB is initiated. Mild hypothermia may be used. Extensive anterior dissection of the trachea is performed, and much care is taken to preserve the small vessels at the posterosuperior and posteroinferior trachea. The total stenotic length and length of autograft required are calculated; typically, a third of the total tracheal length is resected. The posterior trachea is then reapproximated using interrupted PDS. The autograft is sized appropriately and sutured into the inferior aspect of the anterior tracheal opening. Finally, a small pericardial patch may be used to complete the operation. In their series of twenty patients who underwent autograft repair, Backer et al. reported a mortality rate of $20 \%$. Interestingly, all four of these patients had associated complex cardiac anomalies (30). Other groups have had similar outcomes $(25,31)$.

\section{Pericardial patch tracheoplasty}

This operation is of historical interest. It was introduced by Farouk Idriss in 1984, and paved the way for the modern era of tracheal stenosis repair in children (32). Under CPB, the anterior trachea is incised along the entirety of its stenotic length. A fresh piece of autologous pericardium is sewn in to augment the tracheal diameter. The patch is secured to various mediastinal structures to prevent collapse. It is kept stented open by the ETT until "fixation" occurs. One big disadvantage of this operation is the high incidence of granulation tissue formation, resulting in higher mortality rates compared to more contemporary techniques. Interestingly, autopsy examinations of tracheas reconstructed in such a manner have showed the patch to be covered with pseudostratified ciliated columnar epithelium (33).

\section{The controversy}

Some authors have argued that staged correction may be appropriate for certain cases of combined disease $(34,35)$. For instance, Okamoto et al. retrospectively compared the operative outcomes of 10 patients with isolated CTS to: (I) 27 patients with CTS who underwent simultaneous repair of their cardiac anomalies, and (II) 5 patients who underwent staged repair (36). There were 4 deaths among those who underwent concomitant repair, and no deaths in the other groups; all operative mortalities occurred in patients with associated complex cardiac anomalies such as critical PS, TOF with an absent pulmonary valve, and cor triatrium. CPB duration was also a prognostic factor for the outcomes of combined tracheal and cardiac surgery. The authors concluded that CTS with complex cardiac lesions (or cases that would need long CPB support) may benefit from staged repair whereas simple associated heart defects should be repaired at the time of tracheal reconstruction (36).

Recent evidence now suggests that patients with combined disease may undergo simultaneous repair of both lesions with favorable short and mid-term outcomes, regardless of the nature of the associated cardiac anomaly.

In their retrospective review of 21 patients who underwent repair of combined tracheal stenosis and cardiac anomalies, Mainwaring et al. reported 2 deaths, both of which occurred in neonates with a functionally single ventricle (37). Both patients died from complications related to sepsis. None of the patients required major reinterventions on the trachea or bronchi, and 1 patient 
developed heart block after TOF repair. These results suggest that complex cardiac anomalies may, and should, be repaired at the time of tracheal surgery. Interestingly, of the 21 patients who underwent combined repair, 8 patients were found to have tracheal or bronchial stenosis after repair of a previous congenital heart defect. The authors hypothesized that factors such as prolonged intubation, trauma from suctioning, great vessel compression, scar tissue formation, and devascularization may have contributed to the delayed presentation of symptomatic tracheal stenosis. Therefore, a more aggressive approach to the identification of CTS may be indicated in a subset of higher risk patients with cardiac anomalies. Note that $\mathrm{CPB}$ was used in $93 \%$ of the patients in the study, and that slide tracheoplasty or bronchoplasty was the predominant method of tracheal reconstruction (37).

These results have been well validated $(8,38-40)$. In a retrospective review of nine infants who underwent combined tracheal and cardiac surgery at the University of Heidelberg between 2000 and 2003, there was no operative mortality, requirement for tracheostomies, or rehospitalization in the postoperative period. In contrast to the study by Mainwaring et al., the authors here chose resection with end-to-end anastomosis for tracheal reconstruction (41).

In another study by Manning et al., a cohort of 80 patients underwent slide tracheoplasty with CPB support, 24 of whom also had simultaneous repair of a cardiovascular abnormality (17 PAS repairs, 5 VSD closures, 5 ASD closures, 2 TOF repairs, and 1 repair of pulmonary vein stenosis). $\mathrm{CPB}$ duration was associated with mortality $(\mathrm{P}=0.025)$ and multiple regression analysis identified previous airway operation $(\mathrm{P}=0.01)$, need for significant airway reintervention $(\mathrm{P}<0.001)$, and longer $\mathrm{CPB}$ duration as predictors of increased hospital stay (42). Xue et al. also analyzed the outcomes of 43 pediatric patients who underwent combined tracheal and cardiac surgery over a 13 -year period (PAS, $n=31$; TOF, $n=5$; VSD, $\mathrm{n}=4$; ASD, $\mathrm{n}=4$; double aortic arch, $\mathrm{n}=2$; pulmonary atresia with VSD, $\mathrm{n}=1$ ). The authors found that simultaneous repair of associated congenital heart defects did not increase complication rates (43).

As a final example, the group from the Great Ormond Street Hospital for Children reported on 72 patients that underwent combined cardiac and tracheal repair (for longsegment CTS) between 1995 and 2012. Overall survival was $88.2 \%$, and multivariate analysis revealed preoperative extracorporeal membrane oxygenation $(\mathrm{P}<0.05)$, preoperative tracheomalacia $(\mathrm{P}<0.001)$, and bronchial stenosis $(\mathrm{P}<0.05)$ to be adverse predictors of survival (44). All the aforementioned studies reinforce combined tracheal and cardiac repair as the procedure of choice for patients with concomitant disease.

\section{CTS \& PAS}

Aptly named the "ring-sling complex", the relationship between CTS and PAS was first recognized by Walter Berdon in 1984, and was crucial in improving the operative outcomes of patients with such disease (45). Complete tracheal rings are present in approximately $50-65 \%$ of children with PAS (Figure 2) (46). Surgical correction offers the best chance of survival and involves concomitant repair of both defects. A median sternotomy is performed, and extracorporeal circulation is initiated. The trachea is reconstructed as previously described, usually with slide tracheoplasty. For PAS repair, the LPA is transected at its origin from the RPA and anastomosed to the main pulmonary artery (MPA) at a site that approximates its usual anatomic configuration (47). We prefer this operation to the anterior transposition of the LPA.

A progressive understanding of the various pathological and anatomical issues at play, coupled with improvements in surgical techniques, have paved the way for the excellent outcomes seen in the modern era. For instance, Backer et al. reported on 34 patients who underwent PAS repair since 1985, 27 (79\%) of whom had CTS secondary to complete tracheal rings. Tracheal reconstruction techniques included pericardial patch tracheoplasty $(n=7)$, tracheal autograft $(n=10)$, tracheal resection $(n=4)$, and slide tracheoplasty $(n=5)$. There was zero early mortality and four late deaths, two of which were the result of complications from tracheal surgery. All re-implanted LPAs were found to be patent at follow-up (7). These findings validate: (I) simultaneous repair as the surgical treatment of choice for patients with combined disease, and (II) the use of median sternotomy, $\mathrm{CPB}$, and LPA reimplantation into the MPA for PAS repair. Note that since 2004, Backer and associates have used slide tracheoplasty for tracheal reconstruction (14).

In another series of 116 patients with the ring-sling complex that underwent slide tracheoplasty, Chen et al. reported an in-hospital mortality of $6 \%$ along with 8 late deaths. Interestingly, the authors found the presence of additional cardiovascular anomalies to be significantly associated with postoperative tracheomalacia (48).

It should be noted that patients with PAS and mild tracheal narrowing may be managed with PAS repair alone. For instance, Fiore et al. reported on 14 infants with PAS who underwent surgical correction between 1985 and 2002. 
Eight of these patients had CTS and underwent combined repair, while six had mild tracheal disease and underwent PAS repair only. There were two in-hospital deaths, all LPAs were patent at a mean follow-up for 42 months, and no reoperations for tracheal reconstruction were required (49). These findings were affirmed by Hong et al. in their series of 14 patients with PAS and varying degrees of tracheal stenosis (50). Some authors have even suggested a "cutoff" diameter above which only PAS repair should be performed (51). Regardless of the surgical strategy, it is evident that children with PAS and CTS benefit from a holistic, team-based approach and meticulous surveillance pre-and post-operatively $(52,53)$.

\section{Conclusions}

The past 60 years have witnessed a dramatic evolution in the surgical management of CTS associated with cardiovascular anomalies. From the early days of cartilage and pericardial tracheoplasty in the 1980s and the first PAS repair in 1953, we have come a long way in successfully managing this disease process. Current evidence suggests that the best outcomes are achieved when all defects are repaired simultaneously through a median sternotomy and using $\mathrm{CPB}$, and by using the versatile slide tracheoplasty technique for tracheal reconstruction. When mild tracheal narrowing is present, staged repair may be considered. Irrespective of the operative strategy employed, a thorough, multidisciplinary approach to patient management is crucial in ensuring successful outcomes.

\section{Acknowledgments}

Funding: None.

\section{Footnote}

Provenance and Peer Review: This article was commissioned by the Guest Editor (Raghav A. Murthy) for the series "Management of Congenital Heart Disease" published in Fournal of Thoracic Disease. The article was sent for external peer review organized by the Guest Editor and the editorial office.

Conflicts of Interest: The series "Management of Congenital Heart Disease" was commissioned by the editorial office without any funding or sponsorship. RAM serves as the unpaid editorial board member of Fournal of Thoracic Disease from Apr 2019 to Mar 2021 and served as the unpaid Guest Editor of the series. AS has no other conflicts of interest to declare.

Ethical Statement: The authors are accountable for all aspects of the work in ensuring that questions related to the accuracy or integrity of any part of the work are appropriately investigated and resolved.

Open Access Statement: This is an Open Access article distributed in accordance with the Creative Commons Attribution-NonCommercial-NoDerivs 4.0 International License (CC BY-NC-ND 4.0), which permits the noncommercial replication and distribution of the article with the strict proviso that no changes or edits are made and the original work is properly cited (including links to both the formal publication through the relevant DOI and the license). See: https://creativecommons.org/licenses/by-nc-nd/4.0/.

\section{References}

1. Benjamin B, Pitkin J, Cohen D. Congenital tracheal stenosis. Ann Otol Rhinol Laryngol 1981;90:364-71.

2. Wilcox LJ, Schweiger C, Hart CK, et al. Growth and Management of Repaired Complete Tracheal Rings after Slide Tracheoplasty. Otolaryngol Head Neck Surg 2019;161:164-70.

3. Ragalie WS, Mitchell ME. Advances in Surgical Treatment of Congenital Airway Disease. Semin Thorac Cardiovasc Surg 2016;28:62-8.

4. Schweiger C, Cohen AP, Rutter MJ. Tracheal and bronchial stenoses and other obstructive conditions. J Thorac Dis 2016;8:3369-78.

5. Cantrell JR, Guild HG. Congenital Stenosis of the Trachea. Am J Surg 1964;108:297-305.

6. Oshima Y, Yamaguchi M, Yoshimura N, et al. Management of pulmonary artery sling associated with tracheal stenosis. Ann Thorac Surg 2008;86:1334-8.

7. Backer CL, Russell HM, Kaushal S, et al. Pulmonary artery sling: current results with cardiopulmonary bypass. J Thorac Cardiovasc Surg 2012;143:144-51.

8. Backer CL, Mavroudis C, Gerber ME, et al. Tracheal surgery in children: an 18-year review of four techniques. Eur J Cardiothorac Surg 2001;19:777-84.

9. Arcieri L, Moschetti R, Assanta N, et al. Successful simultaneous correction of complex congenital tracheal stenosis and tetralogy of fallot. World J Pediatr Congenit Heart Surg 2012;3:511-4. 
10. Oshima Y, Yamaguchi M, Yoshimura N, et al. Primary repair of pulmonary artery sling with double outlet right ventricle and distal tracheal stenosis. J Cardiovasc Surg (Torino) 2002;43:849-51.

11. Yamaguchi M, Oshima Y, Hosokawa Y, et al. Concomitant repair of congenital tracheal stenosis and complex cardiac anomaly in small children. J Thorac Cardiovasc Surg 1990;100:181-7.

12. Nakayama DK, Harrison MR, de Lorimier AA, et al. Reconstructive surgery for obstructing lesions of the intrathoracic trachea in infants and small children. J Pediatr Surg 1982;17:854-68.

13. Pfammatter JP, Casaulta C, Pavlovic M, et al. Important excess morbidity due to upper airway anomalies in the perioperative course in infant cardiac surgery. Ann Thorac Surg 2006;81:1008-12.

14. Backer CL, Holinger LD. A history of pediatric tracheal surgery. World J Pediatr Congenit Heart Surg 2010;1:344-63.

15. Grillo HC. Surgical approaches to the trachea. Surg Gynecol Obstet 1969;129:347-52.

16. Wright CD, Graham BB, Grillo HC, et al. Pediatric tracheal surgery. Ann Thorac Surg 2002;74:308-13; discussion 314.

17. Cotter CS, Jones DT, Nuss RC, et al. Management of distal tracheal stenosis. Arch Otolaryngol Head Neck Surg 1999; 125:325-8.

18. Wright CD, Grillo HC, Wain JC, et al. Anastomotic complications after tracheal resection: prognostic factors and management. J Thorac Cardiovasc Surg 2004;128:731-9.

19. Jonas RA, Spevak PJ, McGill T, et al. Pulmonary artery sling: primary repair by tracheal resection in infancy. J Thorac Cardiovasc Surg 1989;97:548-50.

20. Tsang V, Murday A, Gillbe C, et al. Slide tracheoplasty for congenital funnel-shaped tracheal stenosis. Ann Thorac Surg 1989;48:632-5.

21. Stephens EH, Eltayeb O, Mongé MC, et al. Pediatric Tracheal Surgery: A 25-year Review of Slide Tracheoplasty and Tracheal Resection. Ann Thorac Surg 2020;109:148-53.

22. Dayan SH, Dunham ME, Backer CL, et al. Slide tracheoplasty in the management of congenital tracheal stenosis. Ann Otol Rhinol Laryngol 1997;106:914-9.

23. Grillo HC, Wright CD, Vlahakes GJ, et al. Management of congenital tracheal stenosis by means of slide tracheoplasty or resection and reconstruction, with longterm follow-up of growth after slide tracheoplasty. J
Thorac Cardiovasc Surg 2002;123:145-52.

24. Kim HK, Kim YT, Sung SW, et al. Management of congenital tracheal stenosis. Eur J Cardiothorac Surg 2004;25:1065-71.

25. Kocyildirim E, Kanani M, Roebuck D, et al. Longsegment tracheal stenosis: slide tracheoplasty and a multidisciplinary approach improve outcomes and reduce costs. J Thorac Cardiovasc Surg 2004;128:876-82.

26. Le Bret E, Roger G, Pezzettigotta S, et al. Slide tracheoplasty in congenital tracheal stenosis. Ann Otolaryngol Chir Cervicofac 2006;123:325-32.

27. Manning PB, Rutter MJ, Border WL. Slide tracheoplasty in infants and children: risk factors for prolonged postoperative ventilatory support. Ann Thorac Surg 2008;85:1187-91; discussion 1191-2.

28. Jacobs JP, Elliott MJ, Haw MP, et al. Pediatric tracheal homograft reconstruction: a novel approach to complex tracheal stenoses in children. J Thorac Cardiovasc Surg 1996;112:1549-58; discussion 1559-60.

29. Backer CL, Mavroudis C, Dunham ME, et al. Repair of congenital tracheal stenosis with a free tracheal autograft. J Thorac Cardiovasc Surg 1998;115:869-74.

30. Backer CL, Holinger LD, Mavroudis C. Congenital Tracheal Stenosis: Tracheal Autograft Technique. Oper Tech Thorac Cardiovasc Surg 2007;12:178-83.

31. Yang JH, Jun TG, Sung K, et al. Repair of longsegment congenital tracheal stenosis. J Korean Med Sci 2007;22:491-6.

32. Idriss FS, DeLeon SY, Ilbawi MN, et al. Tracheoplasty with pericardial patch for extensive tracheal stenosis in infants and children. J Thorac Cardiovasc Surg 1984;88:527-36.

33. Fanous N, Husain SA, Ruzmetov M, et al. Anterior pericardial tracheoplasty for long-segment tracheal stenosis: long-term outcomes. J Thorac Cardiovasc Surg 2010;139:18-23; discussion 23-5.

34. Chiu PP, Kim PC. Prognostic factors in the surgical treatment of congenital tracheal stenosis: a multicenter analysis of the literature. J Pediatr Surg 2006;41:221-5; discussion 221-5.

35. Kwak JG, Kim WH, Min J, et al. Is tracheoplasty necessary for all patients with pulmonary artery sling and tracheal stenosis? Pediatr Cardiol 2013;34:498-503.

36. Okamoto T, Nishijima E, Maruo A, et al. Congenital tracheal stenosis: the prognostic significance of associated cardiovascular anomalies and the optimal timing of surgical treatment. J Pediatr Surg 2009;44:325-8.

37. Mainwaring RD, Shillingford M, Davies R, et al. Surgical 
reconstruction of tracheal stenosis in conjunction with congenital heart defects. Ann Thorac Surg 2012;93:126672; discussion 1272-3.

38. Wang S, Zhang H, Zhu L, et al. Surgical management of congenital tracheal stenosis associated with tracheal bronchus and congenital heart disease. Eur J Cardiothorac Surg 2016;49:1201-6.

39. Backer CL, Mavroudis C, Holinger LD. Repair of congenital tracheal stenosis. Semin Thorac Cardiovasc Surg Pediatr Card Surg Annu 2002;5:173-86.

40. Wu ET, Wang CC, Lin MT, et al. Concomitant slide tracheoplasty and cardiac operation for congenital tracheal stenosis associated with VACTERL. Ann Thorac Surg 2013;96:1492-5.

41. Loukanov T, Sebening C, Springer W, et al. Simultaneous management of congenital tracheal stenosis and cardiac anomalies in infants. J Thorac Cardiovasc Surg 2005;130:1537-41.

42. Manning PB, Rutter MJ, Lisec A, et al. One slide fits all: the versatility of slide tracheoplasty with cardiopulmonary bypass support for airway reconstruction in children. J Thorac Cardiovasc Surg 2011;141:155-61.

43. Xue B, Liang B, Wang S, et al. One-stage surgical correction of congenital tracheal stenosis complicated with congenital heart disease in infants and young children. J Card Surg 2015;30:97-103.

44. Butler CR, Speggiorin S, Rijnberg FM, et al. Outcomes of slide tracheoplasty in 101 children: a 17-year single-center experience. J Thorac Cardiovasc Surg 2014;147:1783-9.

45. Berdon WE, Baker DH, Wung JT, et al. Complete

Cite this article as: Sengupta A, Murthy RA. Congenital tracheal stenosis \& associated cardiac anomalies: operative management \& techniques. J Thorac Dis 2020;12(3):11841193. doi: $10.21037 /$ jtd.2019.10.42 cartilage-ring tracheal stenosis associated with anomalous left pulmonary artery: the ring-sling complex. Radiology 1984;152:57-64.

46. Sade RM, Rosenthal A, Fellows K, et al. Pulmonary artery sling. J Thorac Cardiovasc Surg 1975;69:333-46.

47. Backer CL, Idriss FS, Holinger LD, et al. Pulmonary artery sling. Results of surgical repair in infancy. J Thorac Cardiovasc Surg 1992;103:683-91.

48. Chen H, Shi G, Zhu L, et al. Intermediate-term Outcomes of Slide Tracheoplasty in Pediatric Patients with Ringsling Complex. Ann Thorac Surg 2019. [Epub ahead of print].

49. Fiore AC, Brown JW, Weber TR, et al. Surgical treatment of pulmonary artery sling and tracheal stenosis. Ann Thorac Surg 2005;79:38-46; discussion 38-46.

50. Hong X, Zhou G, Liu Y, et al. Management of pulmonary artery sling with tracheal stenosis: LPA re-implantation without tracheoplasty. Int J Clin Exp Med 2015;8:2741-7.

51. Huang SC, Wu ET, Wang CC, et al. Surgical management of pulmonary artery sling: trachea diameter and outcomes with or without tracheoplasty. Pediatr Pulmonol 2012;47:903-8.

52. Arcieri L, Giordano R, Murzi B. To do or not to do? The management dilemma of congenital tracheal stenosis in the setting of the ring-sling complex. J Thorac Dis 2017;9:4896-8.

53. Torre M. Left pulmonary artery sling and congenital tracheal stenosis: to slide or not to slide? J Thorac Dis 2017;9:4881-3. 